\section{Normalization of Trans- fection Efficiency Using the $\beta$-Lactamase Gene of the pGL3 Luciferase Vector in Primary Anterior Pituitary Cells}

BioTechniques 33:326-330 (August 2002)

\begin{abstract}
The $\beta$-galactosidase reporter gene is commonly used as a control for transfection efficiency in the promoter reporter assay system. While investigating vasoactive intestinal peptide response elements in the promoter of the prolactin gene, we found that primary pituitary cells from turkey hens highly expressed endogenous $\beta$-galactosidase. Therefore, we developed a new protocol for determining transfection efficiency using the $\beta$-lactamase gene, which is present on many expression vectors. Transcript levels of $\beta$-lactamase were measured by $R T$ $P C R$ after transfection of different amounts of the pGL3-basic and pGL3-control vectors. A high correlation was observed between the amount of plasmid transfected and $\beta$-lactamase mRNA levels. Although no eukaryotic promoter was present, there was apparently leaky expression of the $\beta$-lactamase gene. Expression of $\beta$-lactamase was independent of expression from the simian virus 40 or turkey prolactin promoters cloned upstream of the luciferase gene.
\end{abstract}

\section{INTRODUCTION}

One approach to monitoring gene expression is to use fusion genes of the putative promoter elements joined to a gene that encodes a reporter gene, whose enzymatic activity can be detected if the gene is activated (10). The lac Z gene from $E$. coli, which encodes the enzyme $\beta$-galactosidase, is frequently used as a control vector for normalizing transfection efficiency when co-transfected with promoter-reporter gene constructs $(4,5)$. One potential limitation to using this reporter gene is that certain mammalian (2) and avian (this study) cells express endogenous $\beta$-galactosidase activity. We found that $\beta$-galactosidase was highly expressed in turkey primary pituitary cells, which limited the use of the $l a c \mathrm{Z}$ gene as a control vector in turkey prolactin (PRL) promoter (tPRLP) studies. To gain a further understanding of the regulatory mechanism of tPRLP in the pituitary gland, it was necessary to develop an alternative protocol for transfection efficiency normalization in transient transfection studies.

$\beta$-lactamase is the enzyme responsible for bacterial resistance to $\beta$-lactam antibiotics such as ampicillin. The gene encoding $\beta$-lactamase is commonly found on cloning vectors. Therefore, we investigated the use of the $\beta$-lactamase gene present in the pGL3-vector as an alternative gene for transfection normalization. Correlation between the transfected plasmid and expression level of the $\beta$-lactamase gene was tested in tran- sient transfection studies. Luciferase (Luc) mRNAs under the control of the tPRLP and $\beta$-lactamase mRNA expression were quantified by RT-PCR.

\section{MATERIALS AND METHODS \\ Turkey Pituitary Gland Primary Cell Culture}

Pituitary cells were obtained using a modified trypsin/neuraminidase procedure, as described previously $(3,6)$. Cell viability was approximately $94 \%$ using the trypan blue dye exclusion procedure following four days of incubation at $39^{\circ} \mathrm{C}$. Cells were aliquoted to contain the desired number of cells in 5 $\mathrm{mL}$. The cultures were maintained at $39^{\circ} \mathrm{C}$ in a humidified $5 \% \mathrm{CO}_{2} / 95 \%$ air incubator.

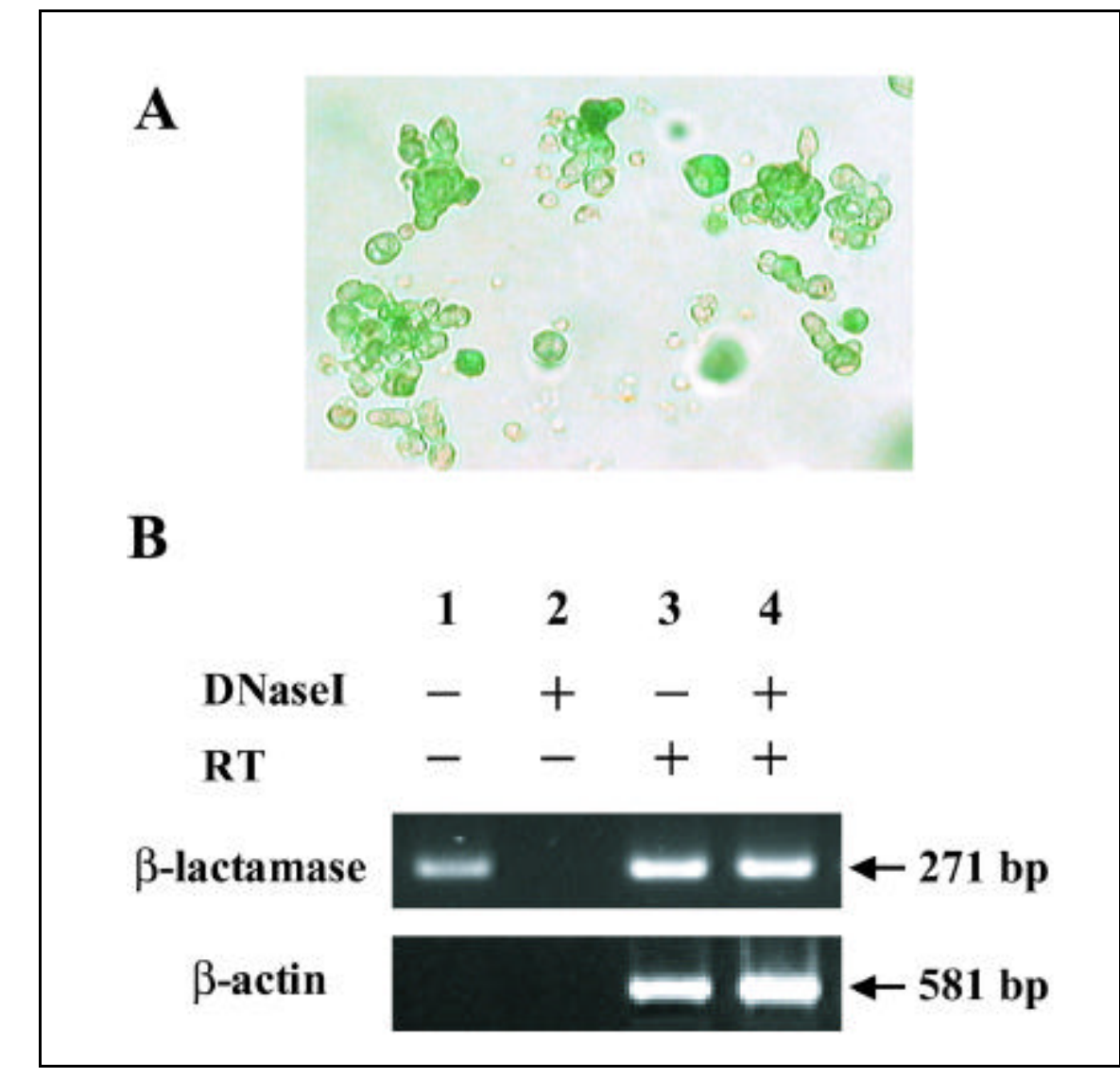

Figure 1. Endogenous $\beta$-galactosidase and detection of $\beta$-lactamase mRNA expression. (A) Primary turkey pituitary cells were stained with $\mathrm{X}$-gal and examined by light microscopy. Photomicrograph was taken with a $40 \times$ objective. (B) The expression of $\beta$-lactamase mRNA after transfection of pGL3-basic plasmid was assayed by RT-PCR. $\beta$-actin mRNA levels served as a control. Two micrograms of RNA were treated with DNase I and repurified. Aliquots were PCR-amplified with the $\beta$-lactamase and $\beta$-actin primers before and after reverse transcription. Single-stranded cDNA was synthesized from $1 \mu \mathrm{g}$ total RNA as described. RT, reverse transcriptase. 


\section{X-Gal Staining of the Primary Anterior Pituitary Cells}

Cells were washed with PBS twice, fixed for $10 \mathrm{~min}$ at room temperature in $2 \%$ formaldehyde $/ 0.2 \%$ glutaraldehyde, washed, and incubated at $37^{\circ} \mathrm{C}$ for 2-4 h with $1 \mathrm{mg}$ fresh $\mathrm{X}$-gal stain solution/mL of solution containing 5 $\mathrm{mM}$ potassium ferrocyanide, $5 \mathrm{mM}$ potassium ferricyanide, $150 \mathrm{mM} \mathrm{NaCl}$, and $2 \mathrm{mM} \mathrm{MgCl}_{2}$. The photomicrograph was taken with a $40 \times$ objective by light microscopy.

\section{Transient Transfection Using Electroporation}

Transient transfections were carried out using electroporation. Briefly, one million cells in $600 \mu \mathrm{L}$ optiMEM ${ }^{\mathrm{TM}} \mathrm{I}$ (Invitrogen, Carlsbad, CA, USA) (5\% FBS) were mixed with $13 \mu \mathrm{g}$ plasmid DNA and exposed to a single discharge of $300 \mu \mathrm{F}$ capacitance and $300 \mathrm{~V}$ in a 4-mm gap cuvette using the Electro Cell Manipulator ${ }^{\mathrm{TM}} 600$ (BTX, San $^{-}$ Diego, CA, USA). Cells were treated with or without chicken vasoactive intestinal peptide (cVIP) $\left(10^{-9} \mathrm{M}\right)$ for $6 \mathrm{~h}$ to observe VIP-stimulated tPRLP activity $24 \mathrm{~h}$ after electroporation. At the conclusion of incubation, cells were collected by centrifugation, washed with $2 \mathrm{~mL}$ PBS, recentrifuged, dissolved in $1 \mathrm{~mL}$ TRIzOL ${ }^{\circledR}$ (Invitrogen), and frozen at $-80^{\circ} \mathrm{C}$.

\section{RT-PCR}

Total RNA was isolated by using TRIzOL, suspended in DEPC-treated sterile water, and quantified by UV spectrometry. To remove the plasmid DNA and genomic DNA contamination, total RNA was treated with $1 \mathrm{U}$ DNase I (Promega, Madison, WI, USA) for $30 \mathrm{~min}$ at $37^{\circ} \mathrm{C}$ in the presence of 40 U RNasin Ribonuclease Inhibitor (Promega) $/ \mu \mathrm{g}$ RNA and heated to $70^{\circ} \mathrm{C}$ for

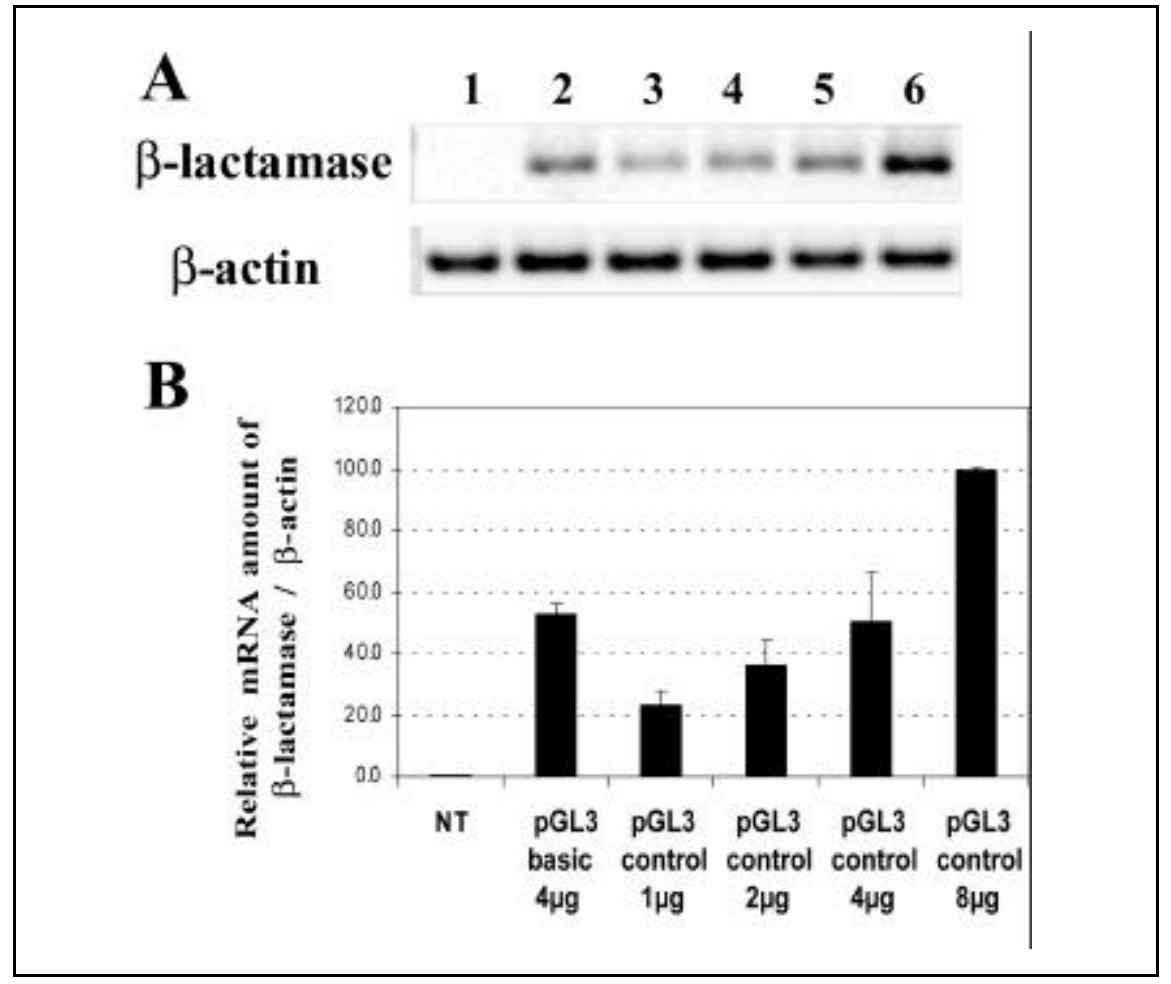

Figure 2. Correlation between the amount of transfected plasmid and expression level of $\beta$-lactamase mRNA. (A) Total RNA was isolated from primary turkey pituitary cells after transfection of different amounts of plasmid (lane 1, nontransfected; lane 2, $4 \mu \mathrm{g}$ pGL3 basic; lane 3, $1 \mu \mathrm{g}$ pGL3 control; lane 4, $2 \mu \mathrm{g}$ pGL3 control; lane 5, $4 \mu \mathrm{g}$ pGL3 control; lane $6,8 \mu \mathrm{g}$ pGL3 control). The $\beta$-lactamase mRNA levels were determined by RT-PCR. (B) The $\beta$-lactamase: $\beta$-actin ratio was analyzed using the Image J program. The relative mRNA amounts of $\beta$-lactamase were normalized to $\beta$-actin mRNA and set to 100 for the $8 \mu \mathrm{g}$ pGL3 control group. The mean values of $\beta$-lactamase mRNA from three independent experiments were plotted with standard deviation. 


\section{Short Technical Reports}

20 min. After DNase I treatment, RNAs were repurified with the RNeasy ${ }^{\mathrm{TM}}$ mini kit (Qiagen, Valencia, CA, USA). Single-stranded cDNA was synthesized from $1 \mu \mathrm{g}$ total cellular RNA using oligo(dT) 16 primer and superscript II RNase H Reverse Transcriptase (Invitrogen), as recommended by the manufacturer. The $\beta$-actin- and $\beta$-lactamasespecific oligonucleotide primers used in the PCR were (i) $\beta$-actin, sense $5^{\prime}$-ACCAGTAATTGGTACCGGCTCCTC-3' and antisense $5^{\prime}$-TCTGGTGGTACCA CAATGTACCCT-3' and (ii) $\beta$-lactamase, sense $5^{\prime}$-TCAGAAGTAAGTTG GCCGCAGTGT-3' and antisense 5'-CAACAGCGGTAAGATCCTTGA GAG-3'. The amplification profile of $\beta$ actin and $\beta$-lactamase consisted of 24 and 22 cycles each for $1 \mathrm{~min}$ at $95^{\circ} \mathrm{C}, 1$ min at $60^{\circ} \mathrm{C}$, and $1 \mathrm{~min}$ at $72^{\circ} \mathrm{C}$, respectively. $\beta$-actin primers made a 581-bp PCR product as previously reported (9), and $\beta$-lactamase primers made a 271-bp PCR product. The reaction products were analyzed by electrophoresis through $3 \%$ agarose and visualized by staining with ethidium bromide. Analysis of the steady-state levels of $\beta$-actin and $\beta$-lactamase mRNAs by RT-PCR were quantified densitometrically by measuring the band intensity of the RTPCR product and normalizing it to the band intensity of $\beta$-actin.

\section{Luc Mimic Construction and Quan- titative RT-PCR}

A mimic construct of the luciferase gene (Luc mimic), which had an internal 111-bp deletion, was constructed (1). Competitive RT-PCR was performed using sense 1 (S1) primer 5'GTGTCGCTCTGCCTCATAGAACTGC-3' and antisense primer 2 (AS2) 5'-GTCTCCAGAATGTAGCCATCCATCC-3' to amplify a 533-bp fragment from the Luc mimic construct and a 644-bp fragment from Luc mRNA. The amplification profile was as follows: denaturation at $95^{\circ} \mathrm{C}$ for $1 \mathrm{~min}$, annealing at $60^{\circ} \mathrm{C}$ for $1 \mathrm{~min}$, and extension at $72^{\circ} \mathrm{C}$ for $1 \mathrm{~min}$. PCR products were run on agarose gels, stained, and photographed with the Eagle Eye II ${ }^{\mathrm{TM}}$ Still Video System (Stratagene, La Jolla, CA, USA), and relative band intensities were determined by the Image $\mathbf{J}$ program (Wayne Rasband, NIH, wayne@codon.nih.gov).
To calculate the relative amount of Luc mRNA in each sample, linear regression analysis was done using Regression Analyzer version 3.2 (MFSoft International; http://www.mfsoft.com).

\section{RESULTS AND DISCUSSION}

Endogenous $\beta$-Galactosidase Activity in the Turkey Primary Pituitary Cells

Cultured turkey primary pituitary cells were stained with X-gal and showed endogenous $\beta$-galactosidase. This prevented us from using the Lac Z coding plasmid cotransfection for a transfection efficiency normalization in our promoter study. Cultured primary cells were kept for 3-4 days in the incubator, stained for endogenous $\beta$-galactosidase activity, and examined by light microscopy. The majority of cells clear- ly showed X-gal staining (Figure 1A). This prevented us from using a LacZ coding plasmid during cotransfection to normalize transfection efficiency in our promoter study. Therefore, we investigated the use of $\beta$-lactamase gene expression for normalization of transfection efficiency. Whether the $\beta$-lactamase transcripts were translated or not was tested by treating transfected cells with ampicillin in the culture media. In this preliminary experiment, transfected cells could tolerate the presence of ampicillin in the culture media.

\section{Detection of $\beta$-Lactamase mRNA Expression after Transient Transfec- tion of pGL3 Luc Vector}

The initial experiment was designed to determine if the $\beta$-lactamase gene was expressed in primary pituitary cells after transfection of the pGL3-vector. The results showed that plasmid conta-

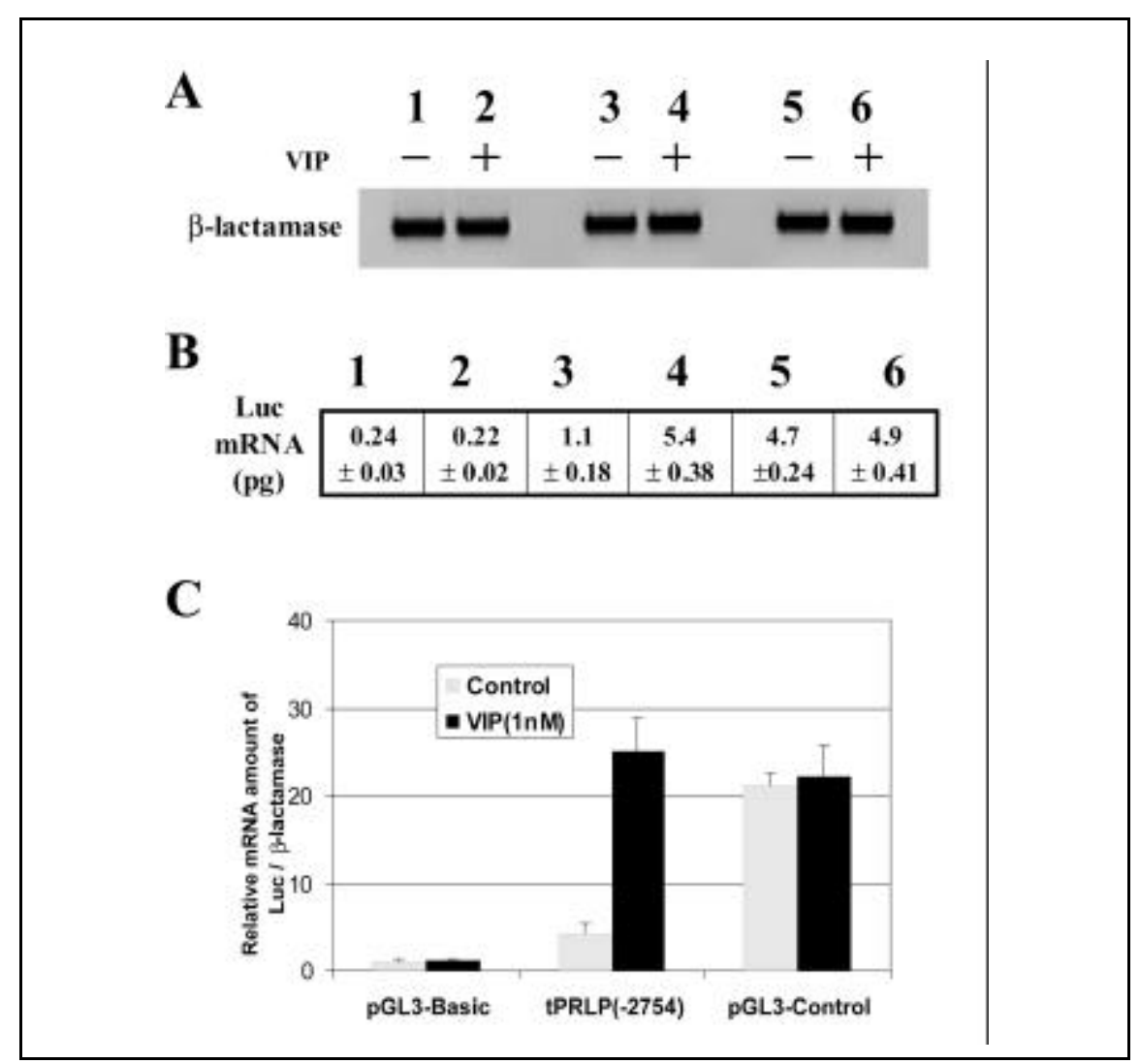

Figure 3. In vitro study of prolactin promoter activity using $\beta$-lactamase gene expression as an internal control. (A) $\beta$-lactamase mRNA was measured by RT-PCR, and (B) Luc mRNAs (pg/ng total RNA) were measured by competitive RT-PCR using Luc mimic cDNA after transfection of plasmids [pGL3-basic, tPRLP(-2754) Luc reporter construct and pGL3-control] in the presence and absence of $\operatorname{cVIP}\left(10^{-9} \mathrm{M}\right)$. (C) The mean values of relative Luc mRNA amount from three independent experiments were plotted with standard deviation after normalizing with the relative value of $\beta$-lactamase. 
mination after RNA extraction was detectable by PCR without reverse transcriptase and DNase I treatment (Figure 1B, lane 1). However, DNase I treatment completely removed the contaminating plasmid DNA (Figure 1B, lane 2). After treating the RNA with DNase I, RT-PCR results showed that $\beta$-lactamase was expressed in this primary pituitary cell culture after transfection of the pGL3-vector (Figure 1B, lane 4). These findings suggest that there is leaky expression of the $\beta$-lactamase gene from the prokaryotic promoter in turkey primary pituitary cells.

\section{Correlation between the Amount of Transfected Plasmid and the Ex- pression Level of $\beta$-Lactamase Gene}

To address the question of a correlation between the amount of transfected plasmid and the expression level of the $\beta$-lactamase gene, different concentrations of pGL3-control and pGL3-basic plasmids were transfected into dispersed pituitary cells $\left(1 \times 10^{6}\right.$ cells $)$. $\beta$-lactamase and $\beta$-actin mRNA levels were measured by RT-PCR after $24 \mathrm{~h}$ (Figure $2 \mathrm{~A}$ ), and data were normalized to $\beta$ actin (Figure 2B). $\beta$-lactamase was not detectable in the nontransfected cells (Figure 2A, lane 1). The expression of $\beta$-lactamase was dependent on the amount of transfected pGL3-control plasmid (Figure 2A, lanes 3-6). The $\beta$ lactamase expression levels from equal amounts of the pGL3-basic (no promoter, lane 2) and pGL3-control (SV40 promoter, lane 5) show that expression from the $\beta$-lactamase gene is independent of the presence of an eukaryotic promoter and enhancer driving Luc gene expression in the pGL3 vector system. Regression analysis performed on normalized $\beta$-lactamase mRNA and the amount of transfected plasmid indicated a correlation coefficient of $r=0.98$.

\section{In Vitro Study of PRL Promoter Activity Using $\beta$-Lactamase Gene Expression as an Internal Control}

Although the expression mechanism of $\beta$-lactamase in eukaryotic cells remains to be clarified, we tested its usefulness as an internal control in an in vitro study of tPRLP activity. We measured $\beta$-lactamase mRNAs (Figure 3A) by RT-
PCR and Luc mRNA (Figure 3B) by competitive RT-PCR using Luc mimic cDNA after transfection of plasmids pGL3-basic (Figure 3, A and B, lanes 1 and 2), tPRLP(-2754) Luc reporter construct (Figure 3, A and B, lanes 3 and 4), and pGL3-control (Figure 3, A and B, lanes 5 and 6). Promoter activity was measured by Luc mRNA amount using competitive RT-PCR. Luc mRNAs were measured from three independent experiments (Figure 3B). The results showed that the TPRLP in the non-VIP-stimulated cells had approximately $21 \%$ activity of pGL3-control (SV40 enhancer and promoter) and was highly stimulated by VIP (1 nM) treatment (105\% of pGL3control) (Figure 3C). These results are in agreement with our previous studies that the steady-state levels of PRL mRNA were increased markedly at the transcriptional level by VIP stimulation $(7,8)$. Thus, $\beta$-lactamase expression can be used as a reliable normalization factor of transfection efficiency.

We describe here a novel transfection efficiency normalization method using the $\beta$-lactamase gene. This method yields a highly efficient result in primary pituitary cells that express endogenous $\beta$-galactosidase, whose presence excludes the use of the exogenous lacZ gene as a control. Unlike conventional cotransfection with another vector, the advantage of this protocol is that no cotransfection is needed because most plasmids already have the $\beta$-lactamase gene. This method will be useful for the analysis of transcriptional activity of different gene promoters in cells that express endogenous $\beta$-galactosidase activity.

\section{REFERENCES}

1.Ali, S.A., I. Sarto, and A. Steinkasserer. 1997. Production of PCR mimics for any semiquantitative PCR application. BioTechniques 22:1060-1062.

2.Dimri, G.P., X. Lee, G. Basile, M. Acosta, G. Scott, C. Roskelley, E.E. Medrano, M. Linskens, et al. 1995. A biomarker that identifies senescent human cells in culture and in aging skin in vivo. Proc. Natl. Acad. Sci. USA 92:9363-9367.

3.Fehrer, S.C., J.L. Silsby, E.J. Behnke, and M.E. EI Halawani. 1985. Hypothalamic and serum factors influence on prolactin and luteinizing hormone release by the pituitary gland of the young turkey (Meleagris gallopavo). Gen. Comp. Endocrinol. 59:73-81.
4.Hall, C.V., P.E. Jacob, G.M. Ringold, and F. Lee. 1983. Expression and regulation of Escherichia coli lacZ gene fusions in mam malian cells. J. Mol. Appl. Genet. 2:101-109.

5.Hollon, T. and F.K. Yoshimura. 1989. Variation in enzymatic transient gene expression assays. Anal. Biochem. 182:411-418.

6.Hopkins, C.R. and M.G. Farquhar. 1973. Hormone secretion by cells dissociated from rat anterior pituitaries. J. Cell. Biol. 59:277303.

7.Tong, Z., G.R. Pitts, S. You, D.N. Foster, and M.E. El Halawani. 1998. Vasoactive intestinal peptide stimulates turkey prolactin gene expression by increasing transcription rate and enhancing mRNA stability. J. Mol. Endocrinol. 21:259-266.

8.Xu, M., J.A. Proudman, G.R. Pitts, E.A. Wong, D.N. Foster, and M.E. El Halawani. 1996. Vasoactive intestinal peptide stimulates prolactin mRNA expression in turkey pituitary cells: effects of dopaminergic drugs. Proc. Soc. Exp. Biol. Med. 212:52-62.

9.You, S., J.L. Silsby, J. Farris, D.N. Foster, and M.E. El Halawani. 1995. Tissue-specific alternative splicing of turkey preprovasoactive intestinal peptide messenger ribonucleic acid, its regulation, and correlation with prolactin secretion. Endocrinology 136:2602-2610.

10.Zlokarnik, G., P.A. Negulescu, T.E. Knapp, L. Mere, N. Burres, L. Feng, M. Whitney, K. Roemer, and R.Y. Tsien. 1998. Quantitation of transcription and clonal selection of single living cells with $\beta$-lactamase as reporter. Science 279:84-88.

The authors wish to thank Mr. Steven E. Whiting and Mr. Thomas Bakken for their excellent technical assistance during this research. This work was supported by USDA grant no. 00-35203-9157. Address correspondence to Dr. Mohamed E. El Halawani, 495 AnSci/VetMed Bldg., 1988 Fitch Ave., St. Paul, MN 55108, USA. email:elhal001@umn.edu

Received 29 November 2001; accepted 25 April 2002.

Seong W. Kang, Seungkwon You ${ }^{1}$, Eric A. Wong², and Mohamed E. El Halawani University of Minnesota

St. Paul, MN, USA

${ }^{1}$ Korea University

Seoul, Korea

${ }^{2}$ Virginia Polytechnic Institute and State University Blacksburg, VA, USA

For reprints of this or any other article, contact Reprints@BioTechniques.com 